\title{
AO ALCANCE DA SOCIEDADE: ANÁLISE DAS AÇÕES DE DIFUSÃO DO CENTRO DE DOCUMENTAÇÃO E MEMÓRIA DA UNESP (2015- 2018)
}

\author{
AT THE REACH OF SOCIETY: ANALYSIS OF THE \\ DISSEMINATION OF THE UNESP DOCUMENTATION \\ AND MEMORY CENTER (2015-2018)
}

Wilson de Jesusa

Sonia Troitiñob

\begin{abstract}
RESUMO
Introdução: A memória coletiva e social é objeto de muitos interesses políticos, ideológicos, econômicos e culturais. Sendo assim, instituições públicas voltadas para a salvaguarda documental assumem um papel central para a preservação da memória. Entre elas, destacamos o Centro de Documentação e Memória (CEDEM) da Universidade Estadual Paulista "Júlio de Mesquita Filho" - UNESP, que se constitui como uma instituição de memória com duas linhas temáticas: Memória Universitária e Memória dos Movimentos Político-sociais Brasileiros Contemporâneos. Objetivo: Analisar as ações de difusão desenvolvidas pelo CEDEM. Metodologia: A metodologia da pesquisa é bibliográfica e descritiva, com base na literatura científica da área de Arquivologia e áreas afins sobre memória, e nos relatórios anuais de gestão no período de 2015 até 2018. Resultados: Verificamos que a instituição tem em suas atividades, ações de difusão que são realizadas para atender a seus objetivos propostos. Conclusões: A instituição preserva, guarda, propicia acesso e faz difusão do patrimônio documental da universidade e dos movimentos sociais, com preocupação na preservação digital e física dos acervos; abordagens de caráter educativo para difusão; inserção das suas discussões em mídias sociais (tais como, Facebook e YouTube); além da criação de um ambiente para debates (realizados na própria sede da instituição e transmitidos online nas mídias sociais, todos abertos e de forma gratuita), destacamos nesse sentido que há reflexões sobre temáticas a respeito de movimentos sociais; política brasileira e internacional; questões de gêneros; lançamentos de livros.
\end{abstract}

Descritores: Centro de Documentação. Centro de Memória. CEDEM. Memória Institucional. Difusão.

\footnotetext{
a Graduando em Arquivologia pela Universidade Estadual Paulista (UNESP). E-mail: wilsontxai@gmail.com

b Doutorado em História Social pela Universidade de São Paulo. Docente do Departamento de Ciências da Informação e do Programa de Pós-Graduação em Ciência da Informação da Universidade Estadual Paulista (UNESP). E-mail: sonia.troitino@unesp.br
} 


\section{INTRODUÇÃO}

As instituições responsáveis pela guarda e difusão do patrimônio documental, artístico e cultural como arquivos, bibliotecas, museus e centros de documentação e memória, são meios para o contato com o passado, quer seja ele recente ou longínquo. Muitas dessas memórias são "vividas por tabela", ou seja, acontecem por meio da interação em grupos e movimentos políticos e sociais (POLLAK, 1992).

Relativo ao conceito de Centro de Documentação (CD) Tessitore (2003, p. 14), o caracteriza enquanto uma "mescla" de arquivo, biblioteca e museu. Porém "[...] sem se identificar com nenhuma delas. Bellotto (2007, p. 35), afirma que "[...] recolher, tratar, transferir, difundir informações é o objetivo convergente de arquivos, bibliotecas, museus e centros de documentação".

Outra instituição, que está relacionada com os objetivos citados acima, são os CM (Centros de Memória), que de acordo com o Manual de Implantação de Centros de Memória, elaborado pelo Itaú Cultural (2013, p. 12), são definidos como "[...] uma área de uma instituição cujo objetivo é reunir, organizar, identificar, conservar e produzir conteúdo e disseminar a documentação histórica para os públicos interno e externo [...]". De acordo com Cavalcanti (2014, p. 102) com base nas autoras Sambaquy (1978) e Ortega (2004), os centros de documentação "surgem na Europa do pós-guerra e com a função de oferecer a seus usuários informações especializadas".

Nesse mesmo sentido, Camargo (2003) esclarece que no Brasil, os centros de documentação surgem na década de 1970 ao se criar um modelo sistemático capaz de atender a informações especializadas. De acordo com Camargo e Goulart (2015), a palavra memória nos remete a ideia de fixação, reconhecimento e evocação de experiências passadas, enquanto a palavra centro, "[...] sugere não apenas uma unidade de controle de tais operações; aponta também para a necessidade de evitar a dispersão e a fragmentação de algo que, na verdade, está em toda parte". (CAMARGO; GOULART, 2015, p. 91).

Centros de documentação e memória (CDMs) criados em universidades 
públicas têm como missão dar sentido público ao patrimônio documental tornando acessível ao maior número possível de pessoas os documentos ali guardados, fazendo o elo entre documento e memória. Neste sentido, são responsáveis pelo recebimento, preservação, guarda, tratamento técnico, acesso e difusão dos acervos de temas específicos de pessoas, organizações ou instituições.

Discutir a respeito dos CDMs, em particular, os de caráter universitário, proporciona sentido ao papel social assumido pela universidade: ensino, pesquisa e extensão.

E, convém destacar que no caso do CEDEM, ao fazer a guarda de importantes acervos de grupos marginalizados e movimentos sociais, a instituição possibilita o alcance da cidadania plena, contribuindo para problematizar e reorganizar o sentido de identidade no indivíduo e sua reconstrução incessante (HEYMANN, 1997).

Diante dessa perspectiva e situando o CEDEM como uma instituição de memória voltado especificamente para a memória universitária da UNESP e para a memória de movimentos político-sociais brasileiros contemporâneos ${ }^{1}$, uma pergunta se coloca: quais têm sido as ações que possibilitam difusão do acervo e da instituição?

O objetivo é analisar as ações de difusão desenvolvidas pela instituição. A metodologia da pesquisa é bibliográfica e descritiva, com base na literatura científica da área de Arquivologia e áreas afins sobre memória, e nos relatórios anuais de gestão no período de 2015 até 2018.

Frisamos, ainda, sobre a importância dos relatórios de gestão do CEDEM que nos permitiu verificar as decisões/ações desenvolvidas nesse período selecionado. Outra contribuição fundamental foi a de que algumas decisões/ações não ocorreram de imediato, pois necessitaram de tempo, convencimento dos atores envolvidos, planejamento, projetos, orçamento etc. Ou seja, é um trabalho constante de gestão.

Assim, verifica-se que a instituição tem em suas atividades, ações de

\footnotetext{
${ }^{1}$ Tais como o Movimento dos trabalhadores Rurais Sem-Terra, a Coleção Vladimir Herzog, entre outros.
} 
difusão que são realizadas para atender a seus objetivos propostos. Entre eles preservar, guardar, propiciar acesso e fazer a difusão do patrimônio documental sob sua guarda, com preocupação na preservação digital e física dos acervos; abordagens de caráter educativo para difusão; inserção das suas discussões em mídias sociais (tais como, Facebook e YouTube); além da criação de um ambiente para debates (realizados na própria sede da instituição e transmitidos online nas mídias sociais, todos abertos e de forma gratuita), destacamos ainda que há reflexões sobre temáticas a respeito de movimentos sociais; política brasileira e internacional; questões de gêneros; lançamentos de livros.

\section{CENTRO DE DOCUMENTAÇÃO E MEMÓRIA DA UNESP (CEDEM): TRAJETÓRIA DE CRIAÇÃO E CARACTERÍSTICAS}

Apresentamos nesse tópico um breve contexto de criação do CEDEM, além de suas linhas de pesquisa, política de acervo e sistema de acesso aos acervos. Para começarmos é importante situar o cenário que existia no Brasil, naquele momento de sua criação, com reivindicações de demandas sociais, políticas, econômicas, culturais entre outras, pois, estávamos no período de redemocratização dos direitos políticos no Brasil, após vinte e um anos de regime civil-militar (1964-1985).

Uma destas demandas para a Universidade Estadual Paulista "Júlio de Mesquita Filho" - UNESP, naquele momento, representado por alguns docentes da área de ciências humanas, era a necessidade de narrar a história e a memória da instituição daquele período, para isso era preciso que a documentação estivesse reunida e organizada em um espaço adequado.

Nesse cenário, o CEDEM estabeleceu-se como um dos lugares que recebeu documentos oriundos da própria universidade e posteriormente de movimentos sociais. Ao se constituir como espaço institucional de uma universidade pública o Cedem atendeu a uma demanda de caráter democrático para que os seus acervos fossem preservados, acessíveis e difundidos. Pois, esses aspectos são relevantes para a geração do conhecimento de interesse coletivos e o diálogo permanente a respeito do direito à informação e à memória 
dentro de espaços públicos, por exemplo na universidade.

O CEDEM é vinculado à Vice-Reitoria da UNESP e foi criado em 1987 por professores da área de ciências humanas, e com a missão inicial de preservar a memória da universidade, pois como afirma Corrêa (1999, p. 79) o centro foi "produto de um processo vivido no interior da universidade". A universidade, nesse momento já tinha uma década de criação e cumpria um papel importante no meio acadêmico, político e social do Brasil.

Referente as linhas do acervo, nota-se que pelo fato do CEDEM ser, desde sua concepção, um centro aglutinador da documentação a respeito à história da memória da UNESP e, posteriormente em 1994, ter recebido de importantes fundos a respeito da história política brasileira contemporânea, ele possui duas linhas de pesquisa na qual constituem o seu acervo, sendo elas: 1. Memória universitária e criada em 1994 a linha 2. Memória dos Movimentos Político-sociais Brasileiros Contemporâneos.

De acordo com Troitiño (2017, p. 4), essa linha 2 representou uma ampliação para o CEDEM "[...] configurando hoje, em termos quantitativos, maior porcentagem de documentos relativos aos movimentos sociais, do que os relativos à memória universitária." Ressalta-se também que a instituição possui uma Biblioteca de Apoio e um Acervo bibliográfico dos fundos custodiados.

Diante de sua responsabilidade social, o centro conta com uma política de acervo elaborada em 2015 que visa preservar, guardar, dar acesso e difundir os acervos. A respeito do papel fundamental da política Troitiño $(2017$, p. 3) argumenta que:

[...] a importância na definição de uma política de formação de acervo reside no fato de além de definir a natureza e linhas de acervo que serão abrigados, versar sobre os critérios que deverão orientar as atividades de avaliação, seleção, aquisição, preservação, assim como as condições de descarte de acervo, quando necessário.

O fato do Cedem possuir uma política de acervo o qual define as linhas (apesar de somente ser elaborada em 2015, mesmo tendo sua criação em 1987), faz com que haja procedimentos norteadores que impactam diretamente na preservação e no acesso do acervo para os usuários. Faz-se presente, nessa discussão, sobre a realidade brasileira dos centros de documentação, em que 
Tanno (2018, p. 95, grifo nosso) argumenta que estes:

[...] nem sempre cumprem com a função de serem referenciadores de uma determinada especialização, pois muitos deles tornam-se uma instituição que reúne, de forma aleatória, conjuntos documentais relacionados a temáticas diversas, não se configurando como centros especializados em uma temática por não possuírem uma linha de acervo definida.

Tanno (2018, p. 96, grifo nosso) considera ainda "alguns problemas sobre os centros de documentação que não possuem linhas de acervos bem definidas" sendo estes:

[...] a reunião de documentos que são inexpressivos, seja pelo número reduzido ou pelo conteúdo pouco revelador, e ainda a dispersão de recursos em instituições onde a falta de verbas é crônica. E, por fim, um centro de documentação sem linhas de acervo bem definidas não consegue construir uma identidade que revele sua importância para a sociedade e para os pesquisadores.

Vale ressaltar que a ação de ter uma política fez e faz com que haja uma coerência temática com o que a instituição se propõe diferente de como era antes, como ressalta Troitiño (2016, p. 36) que "durante décadas os processos de incorporação de acervos tiveram caráter "espontâneo" condicionado a avaliação sem protocolo ou metodologia explicitados".

Relativo ao acesso dos acervos, destacamos a implantação do Sistema de Gestão de Acervos Permanentes (SisAcervo), em 2018, que constitui um sistema de gerenciamento, ao mesmo tempo em que opera como um instrumento de pesquisa ao colocar ao alcance dos pesquisadores, comunidades Unespiana e público em geral o acervo do Cedem. Assim, permitindo pesquisas on-line e ampliando as formas de acesso aos documentos. Outro instrumento fundamental é o Guia do Acervo (MORAES, 2018), instrumento que ganhou uma segunda versão atualizada em 2018.

\section{AÇÕES REALIZADAS PELO CEDEM PARA DIFUNDIR O ACERVO E A INSTITUIÇÃO}

A difusão e/ou a disseminação da informação possui um caráter decisivo na aproximação de mais pessoas aos arquivos públicos, pois visa "aproximar o 
público em geral, com o intuito de dar acesso à informação e fomentar a criação de conhecimentos" (CABRAL, 2012, p. 35-36).

Ainda nesse caminho, da necessidade de propiciar 0 acesso às informações em arquivos públicos, Cabral (2012, p. 35) relata que: "[...] algumas instituições arquivísticas brasileiras promovem palestras, seminários, exposições, debates, lançamentos de obras, entre outras atividades". Garantindo assim, que o maior número de pessoas possa interagir com a instituição. Nesse aspecto:

Cabem ao serviço de difusão cultural duas vias contrárias de ação: a que lança elementos de dentro do arquivo para fora, procurando atingir um campo de abrangência cada vez mais amplo, e a que permite o retorno dessa mesma política, acenando com atrativos no recinto do arquivo. (BELLOTTO, 2007, p. 228).

Nesse sentido, utilizamos como fonte para a análise das ações relativas à difusão do CEDEM, os Relatórios de Gestão Anuais de 2015 até 2018, em específico as seções: 6. Atividades Acadêmicas e Difusão Cultural e 7. Programa de Difusão de Acervo2. Dessa forma, as categorias que compõem os quadros, são respectivamente: ano do relatório anual, atividades acadêmicas e culturais descrição das atividades; identificação do tema das atividades de acordo com a linha de acervo/pesquisa do CEDEM quando há nomeação das palestras organizadas pelo Debate CEDEM; e por fim comentamos os impactos dessas ações.

\section{Quadro 1 - Ações realizadas pelo CEDEM para difundir o acervo e a instituição 2015 até 2016.}

\begin{tabular}{|c|c|c|}
\hline $\begin{array}{c}\text { ATIVIDADES } \\
\text { ACADEEMIICAS } \\
\text { E DIFUSÃO } \\
\text { CULTURAL }\end{array}$ & $\begin{array}{c}\text { DESCRIÇÃO } \\
\text { DAS } \\
\text { ATIVIDADES }\end{array}$ & $\begin{array}{c}\text { IDENTIFICAÇÃO } \\
\text { DO TEMA COM } \\
\text { AS LINHAS } \\
\text { DE ACERVO DO } \\
\text { CEDEM }\end{array}$ \\
\hline \multicolumn{2}{|c|}{2015} \\
\hline & \multicolumn{1}{|c|}{20 Lançamento de livro e debate: Tenho algo a dizer: } \\
& Memórias da Unesp na ditadura (1964 a 1985). & Linha 1 \\
\hline
\end{tabular}

\footnotetext{
${ }^{2}$ As ações - Catálogo da Coleção Vlado e - Livro "Memórias de Sparkenbroke" não estavam nas seções 6 e 7, por entender que se constituem atividades de difusão foram inseridos nesse subtópico.
} 


\begin{tabular}{|c|c|c|}
\hline \multirow{14}{*}{$\begin{array}{l}\text { Ciclo de Debates } \\
\text { CEDEM. }\end{array}$} & $\begin{array}{l}\text { Doação ao Cedem de acervo sobre o jornalista } \\
\text { Vladimir Herzog (1937-1975) e apresentação de } \\
\text { resultados da Comissão da Verdade da Unesp. }\end{array}$ & Linha 2 \\
\hline & Abertura democrática e a razão neoliberal. & Linha 2 \\
\hline & $\begin{array}{l}\text { Contradições da direita contemporânea - } \\
\text { diferentes linhagens do pensamento conservador } \\
\text { brasileiro em sua história recente. }\end{array}$ & Linha 2 \\
\hline & $\begin{array}{l}\text { História do Samba Paulista - encantamento } \\
\text { geográfico: do samba rural ao urbano. }\end{array}$ & Linha 2 \\
\hline & $\begin{array}{l}\text { Década Internacional dos afrodescendentes: } \\
\text { reconhecimento, justiça e desenvolvimento. }\end{array}$ & Linha 2 \\
\hline & $\begin{array}{l}\text { Ditadura e homossexualidades - repressão, } \\
\text { resistência e a busca da verdade. }\end{array}$ & Linha 2 \\
\hline & Mario Schenberg - o cientista e o político. & Linha 2 \\
\hline & Arte e militância durante a ditadura e hoje. & Linha 2 \\
\hline & $\begin{array}{l}\text { Yami no Ichinichi - o crime que abalou a colônia } \\
\text { japonesa no Brasil. }\end{array}$ & Linha 2 \\
\hline & Revolução Russa - um balanço Necessário. & Linha 2 \\
\hline & A casa da vovó (DOI-CODI). & Linha 2 \\
\hline & $\begin{array}{l}\text { Militares e militância - uma relação dialeticamente } \\
\text { conflituosa. }\end{array}$ & Linha 2 \\
\hline & $\begin{array}{l}\text { Irmandades Negras - outro espaço de luta e } \\
\text { resistência (São Paulo: } 1870 \text { - 1890). }\end{array}$ & Linha 2 \\
\hline & $\begin{array}{l}\text { Tornando-se livre - a abolição em novas } \\
\text { perspectivas. }\end{array}$ & Linha 2 \\
\hline \multirow{3}{*}{$\begin{array}{l}\text { Eventos } \\
\text { promovidos pelo } \\
\text { CEDEM. }\end{array}$} & Lançamento do livro: Tenho algo a Dizer. & Linha 2 \\
\hline & Comissão da Verdade da Unesp. & Linhas 1 e 2 \\
\hline & Evento de Entrega do Acervo do Vladimir Herzog. & Linha 2 \\
\hline \multirow{9}{*}{$\begin{array}{l}\text { Eventos } \\
\text { promovidos em } \\
\text { parceria com o } \\
\text { CEDEM. }\end{array}$} & $\begin{array}{l}\text { Associação de Arquivistas de São Paulo. (Nome do } \\
\text { evento não identificado }{ }^{3} \text { ) }\end{array}$ & Não se aplica \\
\hline & $\begin{array}{l}\text { "Introdução à História Oral." Associação de } \\
\text { Arquivistas de São Paulo. }\end{array}$ & Não se aplica \\
\hline & 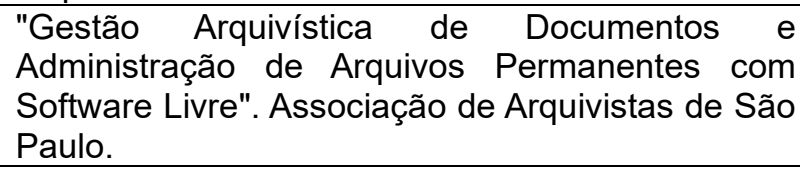 & Não se aplica \\
\hline & $\begin{array}{l}\text { "Digitalização de documentos". Associação de } \\
\text { Arquivistas de São Paulo. }\end{array}$ & Não se aplica \\
\hline & $\begin{array}{l}\text { "Exposição - O Centenário da Revista Feminina } \\
\text { (1915-1936)". Arquivo Público do Estado de São } \\
\text { Paulo. }\end{array}$ & Não se aplica \\
\hline & $\begin{array}{l}\text { Colóquio internacional e interdisciplinar - USP e } \\
\text { Unesp. } \\
\text { Marginalidade Feminina no Mundo Lusófono. }\end{array}$ & Não se aplica \\
\hline & $\begin{array}{l}\text { Treinamento CADA - "Lançamento do Manual de } \\
\text { Protocolo". }\end{array}$ & Não se aplica \\
\hline & $\begin{array}{l}\text { XI Congresso de Arquivologia do Mercosul. } \\
\text { Associação de Arquivistas de São Paulo. }\end{array}$ & Não se aplica \\
\hline & $\begin{array}{l}\text { Comemoração aos } 80 \text { anos do levante da ANL } \\
\text { junto à Fundação Maurício Grabois. }\end{array}$ & Não se aplica \\
\hline
\end{tabular}

\footnotetext{
${ }^{3}$ No relatório analisado não constam essa informação também.
} 


\begin{tabular}{|c|c|c|}
\hline & $\begin{array}{l}\text { Participação Mesa Redonda "Preservação de } \\
\text { Memória Ciência e Tecnologia no Brasil" e "Arquivo } \\
\text { e "Centro de Memória: semelhanças e diferença na } \\
\text { constituição de acervos e tratamento documental." } \\
\text { Participação da mesa. Evento realizado pelo IPT - } \\
\text { Instituto de Pesquisas Tecnológicas. }\end{array}$ & Não se aplica \\
\hline \multicolumn{3}{|c|}{2016} \\
\hline \multirow{15}{*}{$\begin{array}{l}\text { Ciclo de Debates } \\
\text { CEDEM. }\end{array}$} & O Brasil na Segunda Guerra Mundial. & Linha 2 \\
\hline & Memórias da Construção de uma Universidade. & Linha 1 \\
\hline & $\begin{array}{l}\text { Já se passaram } 52 \text { anos - O Golpe Civil Militar de } \\
1964 \text { resistências democrática: um relato por suas } \\
\text { vozes. }\end{array}$ & Linha 2 \\
\hline & O sistema de Cotas e a Universidade Pública & Linha 1 \\
\hline & $\begin{array}{l}\text { Os Arquivos do Comunismo e a Problemática de } \\
\text { sua Preservação. }\end{array}$ & Linha 2 \\
\hline & $\begin{array}{l}\text { Produção do Conhecimento e políticas editoriais } \\
\text { em Universidades. }\end{array}$ & Linha 1 \\
\hline & Revolução Francesa e Social Democracia. & Linha 2 \\
\hline & $\begin{array}{l}\text { Mãos Limpas e Lava Jato: convergências e } \\
\text { divergências. }\end{array}$ & Linha 2 \\
\hline & Mulheres e a Universidade. & Linha 1 \\
\hline & $\begin{array}{l}\text { Caio Prado Júnior - O grande Historiador do século } \\
X X \text {. }\end{array}$ & Linha 2 \\
\hline & Ciência e política: uma visão interdisciplinar. & Linha 2 \\
\hline & Imigração Política Luta e Memória. & Linha 2 \\
\hline & Livros Raros. & Linha 1 \\
\hline & Imprensa Negra - Clóvis Moura. & Linha 2 \\
\hline & $\begin{array}{l}\text { Imprensa negra nos EUA: Chicago. "Defender e a } \\
\text { integração do afroamericano". }\end{array}$ & Linha 2 \\
\hline \multirow{9}{*}{$\begin{array}{l}\text { Eventos } \\
\text { promovidos em } \\
\text { parceria com o } \\
\text { CEDEM. }\end{array}$} & Evento - Lei de acesso à Informação. & Não se aplica \\
\hline & $\begin{array}{l}\text { Colóquio internacional e interdisciplinar - USP e } \\
\text { Unesp. } \\
\text { "Fidelino de Figueiredo" }\end{array}$ & Não se aplica \\
\hline & $\begin{array}{l}\text { Gravação de matérias para TV Aberta. "Processos } \\
\text { de arquivamento e depoimentos" }\end{array}$ & Linha 2 \\
\hline & Entrevista TV Cultura. "Os 40 anos da Unesp". & Linha 1 \\
\hline & $\begin{array}{l}\text { Seminário “Júlio Prestes, o último presidente da } \\
\text { República Velha: arquivo privado de um homem } \\
\text { público". Participação da mesa. }\end{array}$ & Não se aplica \\
\hline & $\begin{array}{l}4^{\circ} \text { Seminário Internacional. "O mundo dos } \\
\text { trabalhadores e seus arquivos: memória, verdade, } \\
\text { justiça e reparação". Participação da mesa. }\end{array}$ & Linha 2 \\
\hline & $\begin{array}{l}\text { Gravação de matéria para TV Aberta. "Gestão de } \\
\text { Reitores" }\end{array}$ & Não se aplica \\
\hline & $\begin{array}{l}\text { Seminário "Centro de memória da Unicamp". } \\
\text { Participação da mesa. }\end{array}$ & Linha 1 \\
\hline & $\begin{array}{l}\text { Colóquio internacional e interdisciplinar - USP e } \\
\text { Unesp. "Oitocentistas". }\end{array}$ & Não se aplica \\
\hline
\end{tabular}




\begin{tabular}{|l|l|l}
\hline $\begin{array}{l}\text { Catálogo da } \\
\begin{array}{l}\text { Coleção Vlado } \\
\text { (Vladimir Herzog). }\end{array}\end{array}$ & $\begin{array}{l}\text { Catálogo elaborado em Excel, com consulta } \\
\text { presencial. }\end{array}$ & Linha 2 \\
\hline
\end{tabular}

Fonte: Elaborado pelos autores com base no Relatório Anual de Gestão 2015 até 2016.

Referente à realização dos Debates CEDEM em 2015, verificamos que $93,3 \%$ diz respeito à linha 2. Quanto à audiência presencial tiveram um total de 1.129 pessoas e neste mesmo ano não havia transmissão on-line. Já em 2016, a temática da linha 2 aparece com $66,6 \%$ dos debates realizados, totalizando uma audiência presencial de 1.145 pessoas.

\section{Sobre os Eventos realizados pelo CEDEM e Eventos realizados em} parceria com o CEDEM verificamos que tais ações permitem aproximações de públicos e de promoção de parcerias institucionais.

A elaboração do Catálogo da Coleção Vlado (Vladimir Herzog) permite o acesso à informação por meio da organização e representação dos conteúdos, o que torna possível a realização das pesquisas.

\section{Quadro 2 - Ações realizadas pelo CEDEM para difundir o acervo e a instituição em 2017.}

\begin{tabular}{|c|c|c|}
\hline $\begin{array}{c}\text { ATIVIDADES } \\
\text { ACADÊMICAS E } \\
\text { DIFUSÃO } \\
\text { CULTURAL }\end{array}$ & DESCRIÇÃO DAS ATIVIDADES & $\begin{array}{c}\text { IDENTIFICAÇÃO } \\
\text { DO TEMA COM AS } \\
\text { LINHAS } \\
\text { DE ACERVO DO } \\
\text { CEDEM }\end{array}$ \\
\hline $\begin{array}{l}\text { Elaboração da } \\
\text { Identidade Visual } \\
30 \text { anos CEDEM. }\end{array}$ & $\begin{array}{l}\text { Foi concebida uma releitura do tradicional logo } \\
\text { do CEDEM, em virtude dos } 30 \text { anos da existência } \\
\text { da instituição. }\end{array}$ & Não se aplica \\
\hline \multirow{10}{*}{$\begin{array}{l}\text { Ciclo de } \\
\text { Debates CEDEM } \\
30 \text { Anos } \\
\text { (Recebeu uma } \\
\text { programação } \\
\text { especial). }\end{array}$} & $\begin{array}{l}\text { A Revolução Soviética e a formação do Partido } \\
\text { Comunista do Brasil (PCB). }\end{array}$ & Linha 2 \\
\hline & Violência contra a mulher em situação de rua. & Linha 2 \\
\hline & $\begin{array}{lllll} & \text { lugar do jornalismo em um mundo } \\
\text { interconectado e dividido. }\end{array}$ & Linha 2 \\
\hline & $\begin{array}{l}\text { A influência da Revolução Russa na trajetória de } \\
\text { um metalúrgico negro. }\end{array}$ & Linha 2 \\
\hline & A Grande Estratégia do Brasil. & Linha 2 \\
\hline & $\begin{array}{l}\text { Interrogando a testemunha: imagens como } \\
\text { Evidências. }\end{array}$ & Linha 2 \\
\hline & $\begin{array}{l}100 \text { anos da Greve Geral de 1917: Marco na } \\
\text { história da classe operária. }\end{array}$ & Linha 2 \\
\hline & $\begin{array}{l}\text { Vida e obra de Antônio Gramsci nos } 80 \text { anos de } \\
\text { sua morte. }\end{array}$ & Linha 2 \\
\hline & $\begin{array}{l}\text { Patrimônio Paulista: políticas de tombamento e } \\
\text { preservação. }\end{array}$ & Linha 1 \\
\hline & $\begin{array}{l}\text { Documentos originais: consequências sociais da } \\
\text { queima de arquivo. }\end{array}$ & Linha 2 \\
\hline
\end{tabular}




\begin{tabular}{|c|c|c|}
\hline & $\begin{array}{l}\text { Sindicalismo em Europa e Brasil: três décadas de } \\
\text { mudança. }\end{array}$ & Linha 2 \\
\hline & $\begin{array}{l}1917 \text { Uma Revolução Confiscada: diálogos com } \\
\text { Vitor Letízia. }\end{array}$ & Linha 2 \\
\hline & $\begin{array}{l}\text { Política externa para a África como instrumento } \\
\text { de ação afirmativa contra o racismo. }\end{array}$ & Linha 2 \\
\hline \multirow{4}{*}{$\begin{array}{l}\text { Eventos } \\
\text { promovidos pelo } \\
\text { CEDEM. }\end{array}$} & Workshop de Conservação Preventiva. & Não se aplica \\
\hline & $\begin{array}{l}\text { Workshop Processo de Criação de llustração } \\
\text { em Editoras. }\end{array}$ & Não se aplica \\
\hline & $\begin{array}{l}\text { Seminário Dimensões e Perspectivas dos } \\
\text { Centros de Memória - } 30 \text { anos CEDEM. }\end{array}$ & Linha 1 \\
\hline & $\begin{array}{l}\text { Fórum dos Centros de Documentação e } \\
\text { Memória da Unesp. }\end{array}$ & Linha 1 \\
\hline \multirow{4}{*}{$\begin{array}{l}\text { Encontros e } \\
\text { eventos } \\
\text { promovidos em } \\
\text { parceria com } \\
\text { diversas } \\
\text { entidades e o } \\
\text { CEDEM. }\end{array}$} & $\begin{array}{l}\text { Reunião do Fórum Pró-Rede de Arquivos } \\
\text { (REDARQ) (7 encontros no total). }\end{array}$ & Não se aplica \\
\hline & $\begin{array}{l}\text { Reunião com Prof. John French (Duke } \\
\text { University), } \\
\text { CEDEM e AREX/Unesp - Projeto } \\
\text { Interinstitucional. }\end{array}$ & Não se aplica \\
\hline & $\begin{array}{l}\text { Seminário arquivos Acadêmicos: Memória, } \\
\text { Pesquisas e Extensão. }\end{array}$ & Linha 1 \\
\hline & $\begin{array}{l}\text { Rede Debate: Um novo marco legal para os } \\
\text { documentos digitais? }\end{array}$ & Não se aplica \\
\hline $\begin{array}{l}\text { Parceria entre o } \\
\text { CEDEM e a } \\
\text { Rádio Unesp FM. }\end{array}$ & $\begin{array}{l}\text { Uma parceria entre o CEDEM e a rádio Unesp } \\
\text { (Bauru), com pequenas audições. }\end{array}$ & Não se aplica \\
\hline $\begin{array}{l}\text { Parceria entre o } \\
\text { CEDEM e a TV } \\
\text { Unesp. }\end{array}$ & $\begin{array}{l}\text { Em maio de 2017, o CEDEM inaugurou um canal } \\
\text { online no site da TV UNESP, a partir de então, } \\
\text { todos os eventos realizados no centro, são } \\
\text { realizados com transmissão simultânea. }\end{array}$ & Não se aplica \\
\hline $\begin{array}{ll}\text { Página } & \text { do } \\
\text { Facebook. } & \end{array}$ & Foi criada oficialmente em dezembro de 2016. & Não se aplica \\
\hline Site Institucional. & $\begin{array}{l}\text { Em } 2017 \text { a periocidade do site do CEDEM } \\
\text { aumentou, chegando a } 74 \text { matérias editadas e } \\
\text { publicadas. }\end{array}$ & Não se aplica \\
\hline $\begin{array}{l}\text { Lançamento do } \\
\text { canal do Cedem } \\
\text { no YouTube. }\end{array}$ & Sem descrição no relatório. & Não se aplica \\
\hline
\end{tabular}

Fonte: Elaborado pelos autores com base no Relatório Anual de Gestão de 2017.

Em relação à ação da Identidade Visual 30 anos, nota-se o impacto na divulgação e comemoração do aniversário de 30 anos da instituição.

As realizações dos Debates Cedem estes com programação especial, têm como impacto a discussão de ideias acerca de temas contemporâneos que conversam com o acervo, além de também aproximar pessoas fisicamente da instituição e/ou virtualmente quando há transmissão online. Verificamos que $92,3 \%$ diz respeito à linha 2. Quanto à audiência presencial tiveram um total de 1.252 pessoas e a audiência on-line foi de 2.000 pessoas. 
Com a Parceria entre o CEDEM e a Rádio Unesp FM, notamos o impacto na difusão de forma ampla, pois considerando o rádio um meio de comunicação ainda muito popular na nossa sociedade, apesar das redes sociais, essa ação propicia de maneira didática a apresentação dos fundos e coleções do CEDEM a um público diverso, por meio de um conteúdo sintético e objetivo, além do impacto sobre a visibilidade da instituição, pois o CEDEM amplia sua abrangência visual em todas as unidades da UNESP, atingindo a comunidade unespiana ou população local.

A conta do CEDEM no Facebook contribui na visualização e na divulgação de seus eventos, projetos e o acervo da instituição ampliando, com isso, o canal de acesso com novos públicos. Nota-se ainda que os seguidores possuem perfil universitário na área de humanidades, interessados em cultura em geral. De acordo com o relatório em 2017 tiveram 111 postagens e foram criados 17 eventos. Tais atividades tiveram como resultado 524 seguidores, até 30 de novembro de 2017.

Em relação ao Site Institucional por ser um portal do CEDEM, nesse caso, há um impacto de visibilidade referente aos objetivos institucionais, acadêmicos e culturais. O relatório aponta que em 2017 a periodicidade do site aumentou. No mês de novembro, contou um total de 74 matérias editadas e publicadas com a média de 100 leituras para cada uma. O site oferece para o usuário da comunidade acadêmica universitária e o público em geral, a possibilidade de acesso aos conteúdos, além do ao guia do acervo, a política do acervo, as publicações, documento do mês, o link para as discussões recentes disponíveis no Youtube, entre outros conteúdos.

Ter um Canal no Youtube do CEDEM, é fundamental ainda mais pelo fato do Youtube ser uma plataforma mundial de compartilhamento de vídeos, é estratégico para o CEDEM ter seus debates divulgados ali, pois, amplia à um público diverso.

Porém, do ponto de vista de acesso aos temas debatidos, que são muitos, notamos a ausência de uma playlist, que se houvesse, facilitaria o acesso aos temas debatidos, organizado por categorias. Esse aspecto revela a necessidade de ter uma equipe técnica específica para essas questões, de tecnologias de 
informação e comunicação na internet.

Vale destacar que o CEDEM assim, como outras instituições, diante dessa nova realidade de uma cultura cada vez mais conectada a dispositivos móveis, pode ter que lidar com uma baixa procura de seu público em seu espaço físico e um grande público online, o que não representa um problema, mas uma adequação e investimento na comunicação com este público.

\section{Quadro 3 - Ações realizadas pelo CEDEM para difundir o acervo e a instituição em 2018.}

\begin{tabular}{|c|c|c|}
\hline $\begin{array}{l}\text { ATIVIDADES } \\
\text { ACADÊMICAS } \\
\text { E DIFUSÃO } \\
\text { CULTURAL }\end{array}$ & $\begin{array}{l}\text { DESCRIÇÃO } \\
\text { DAS } \\
\text { ATIVIDADES }\end{array}$ & $\begin{array}{l}\text { IDENTIFICAÇÃO } \\
\text { DO TEMA COM } \\
\text { AS LINHAS } \\
\text { DE ACERVO DO } \\
\text { CEDEM }\end{array}$ \\
\hline $\begin{array}{lr}\text { Produção do } & \text { livro } \\
\text { "Memórias } & \text { de } \\
\text { Sparkenbroke". } & \end{array}$ & $\begin{array}{l}\text { Entre os acervos disponíveis no CEDEM, } \\
\text { destacamos o "Fundo Clóvis Moura" de } \\
\text { propriedade da Unesp desde } 2004 \text {, constituído } \\
\text { por } 86 \text { caixas arquivo, } 230 \text { pastas, } 400 \text { títulos de } \\
\text { jornais e } 17 \text { livros. }\end{array}$ & Linha 2 \\
\hline $\begin{array}{l}\text { Produção da } 2^{\circ} \\
\text { edição do Guia do } \\
\text { Acervo do CEDEM. }\end{array}$ & $\begin{array}{l}\text { Visa apresentar a comunidade científica e a } \\
\text { sociedade à relação de arquivos e coleções sob } \\
\text { sua tutela e preservados. }\end{array}$ & Linha 2 \\
\hline $\begin{array}{l}\text { Produção de Folder } \\
\text { Institucional. }\end{array}$ & Edição do novo folder do Cedem. & Não se aplica \\
\hline \multirow{10}{*}{$\begin{array}{l}\text { Ciclo de } \\
\text { Debates CEDEM. }\end{array}$} & $\begin{array}{l}\text { Protagonismo político das mulheres no } \\
\text { Movimento do Custo de Vida: } 40 \text { anos dos clubes } \\
\text { de mães da zona sul. }\end{array}$ & Linha 2 \\
\hline & Conservadorismo e nova direita no Brasil. & Linha 2 \\
\hline & $\begin{array}{l}\text { Marx } 200 \text { anos - Por onde deve começar a } \\
\text { ciência? }\end{array}$ & Linha 2 \\
\hline & $\begin{array}{l}\text { 1968: Movimento estudantil e ditadura militar no } \\
\text { Brasil. }\end{array}$ & Linha 2 \\
\hline & $\begin{array}{l}\text { Itinerários para uma esquerda democrática - } \\
\text { Lançamento do livro: Itinerários para uma } \\
\text { esquerda democrática. }\end{array}$ & Linha 2 \\
\hline & $\begin{array}{l}40 \text { anos do Movimento Negro Unificado e } 30 \text { do } \\
\text { Geledés contra o racismo. }\end{array}$ & Linha 2 \\
\hline & $\begin{array}{l}\text { Militares e política no Brasil. Lançamento do livro } \\
\text { homônimo organizado por Paulo Cunha e outros } \\
\text { - Expressão Popular. }\end{array}$ & Linha 2 \\
\hline & $\begin{array}{l}\text { Como combater a desinformação nas redes } \\
\text { digitais. }\end{array}$ & Linha 2 \\
\hline & $\begin{array}{l}\text { Estratégias e desafios para preservação de } \\
\text { informação digital. }\end{array}$ & Linha 1 \\
\hline & $\begin{array}{l}\text { História e memória do movimento guerrilheiro do } \\
\text { Araguaia. }\end{array}$ & Linha 2 \\
\hline \multirow{2}{*}{$\begin{array}{l}\text { Eventos promovidos } \\
\text { pelo CEDEM em }\end{array}$} & $\begin{array}{l}\text { Conferência: La situación del neozapatismo } \\
\text { mexicano en } 2018 \text {. }\end{array}$ & Linha 2 \\
\hline & I Conferência sobre Preservação Digital da & Não se aplica \\
\hline
\end{tabular}




\begin{tabular}{|c|c|c|}
\hline \multirow{2}{*}{$\begin{array}{l}\text { parceria com outros } \\
\text { órgãos. }\end{array}$} & \multicolumn{2}{|l|}{ Unesp. } \\
\hline & $\begin{array}{l}\text { Seminário Políticas Públicas em Arquivos de } \\
\text { Universidades. }\end{array}$ & Linha 1 \\
\hline $\begin{array}{l}\text { Página do } \\
\text { Facebook. }\end{array}$ & $\begin{array}{l}\text { Em } 2018 \text { foram realizadas } 176 \text { postagens e } \\
\text { criados } 13 \text { eventos. Essas atividades resultaram } \\
\text { em } 219 \text { novos seguidores em relação ao mês de } \\
\text { novembro de } 2017 \text {. O alcance das publicações } \\
\text { representa o número de pessoas que tiveram } \\
\text { acesso a elas. Esse alcance varia conforme o } \\
\text { tema. No total, as publicações alcançaram } 47.384 \\
\text { internautas. Os seguidores da fanpage do } \\
\text { CEDEM têm perfil universitário da área de } \\
\text { humanidades, interessados em cultura em geral. }\end{array}$ & Não se aplica \\
\hline Site Institucional. & $\begin{array}{l}\text { No ano de } 2018 \text { foram publicadas } 71 \text { notícias com } \\
\text { o total de envolvimento de } 6.205 \text { internautas. } \\
\text { Essas notícias refletem toda a produção de } \\
\text { conteúdo da comunicação do CEDEM. Nesse } \\
\text { espaço virtual são postadas as divulgações dos } \\
\text { Debates CEDEM, as produções para a Rádio } \\
\text { Unesp FM, matérias específicas sobre os acervos } \\
\text { do Centro, notas sobre livros, entre outras. Todas } \\
\text { elas são reproduzidas na Fanpage do Facebook } \\
\text { e algumas delas alimentam o Portal da Unesp. }\end{array}$ & Não se aplica \\
\hline $\begin{array}{l}\text { Produção do } \\
\text { Documento do Mês. }\end{array}$ & $\begin{array}{l}\text { Espaço na página do CEDEM destinado à } \\
\text { divulgação de seu acervo com foco em um tema } \\
\text { relativo ao mês. As produções são atualizadas } \\
\text { mensalmente e as postagens anteriores } \\
\text { continuam disponíveis para consulta. Assim, o } \\
\text { número de visualizações continua aumentando. } \\
\text { Neste ano de } 2018 \text {, até o início do mês de } \\
\text { dezembro, as visualizações somaram um total de } \\
1.721 \text { internautas. }\end{array}$ & Linhas 1 e 2 \\
\hline $\begin{array}{l}\text { Projeto Conhecendo } \\
\text { o Acervo. }\end{array}$ & $\begin{array}{l}\text { Com intuito de difundir o potencial de pesquisa e } \\
\text { divulgar documentos históricos, pertencentes aos } \\
\text { Fundos geridos pelo Cedem, em } 2018 \text { iniciou-se } \\
\text { o projeto "Conhecendo o Acervo". Trata da } \\
\text { publicação de um conjunto de reportagens sobre } \\
\text { efemérides das quais os acervos do Cedem se } \\
\text { relacionam. }\end{array}$ & Linhas 1 e 2 \\
\hline
\end{tabular}

Fonte: Elaborado pelos autores com base no Relatório Anual de Gestão de 2018.

A ação de organizar o Livro "Memórias de Sparkenbroke" ressalta que a publicação de livros possibilita aos pesquisadores mais um instrumento para a análise dessa informação especializada do fundo, e contribui para que outras pessoas acessem ou possam conhecer sobre parte da vida do intelectual brasileiro Clóvis Moura.

A produção da $2^{\circ}$ edição do Guia do Acervo do CEDEM impactou no acesso ao acervo da instituição, pois um guia constitui um instrumento essencial para o acesso à informação contida na documentação. 
O guia foi elaborado com base nos padrões de descrição pela Norma Brasileira de Descrição Arquivística (NOBRADE).

Em relação aos Debates CEDEM de 2018, verificamos que 90\% dos eventos correspondem a temáticas referente a linha 2 da instituição. Neste relatório anual de gestão (TROITIÑO, 2019) consta, em termos quantitativos, que com os debates as duas conferências e um seminário, houve a presença de 538 pessoas enquanto na audiência on-line foram de 1.182 pessoas.

A criação de uma página institucional do CEDEM no Facebook, aumenta o contato com o seu público tradicional e, simultaneamente, com novos interessados (novos seguidores) que tem impacto na divulgação dos eventos, publicações e tantas outras possibilidades de comunicação realizada diretamente pelo CEDEM. De acordo com o relatório 2018 foram criadas 176 postagens e 13 eventos, que resultaram em 219 novos seguidores em relação ao mês de novembro de 2017. As publicações alcançaram 47.384 internautas. Em relação aos seguidores os perfis se mantêm o mesmo, sendo universitários da área de humanidades, interessados em cultura em geral.

De acordo como relatório Site Institucional do CEDEM, teve o envolvimento de 6.205 internautas, sendo publicadas 71 notícias. Importante ressaltar que "essas notícias refletem toda a produção de conteúdo da comunicação do CEDEM". (TROITIÑO, 2019).

Com a ação de difusão Produção do Documento do Mês e do Projeto Conhecendo o Acervo, notamos o impacto desta ação para chamar novos públicos, inicialmente sem fins de pesquisa acadêmica, mas de interesse de modo geral, ligado à história contemporânea do país. Destaca-se que esse tipo de difusão é de natureza educativa. O relatório apresenta que até o início do mês de dezembro havia um total de 1.721 internautas referente a difusão de produção do documento do mês.

Em síntese, referente a análises dos quadros apresentados, é possível constatar que o CEDEM por meio de seus objetivos, realiza em diferentes ações, aspecto que em sua maioria são de caráter arquivístico, tal fator é explicado por Tessitore (2003, p. 15) ao abordar que os CD "se aproximam do perfil dos arquivos, na medida em que recolhem originais ou reproduções de conjuntos 
arquivísticos".

Em relação as atividades desenvolvidas, notamos que a visão arquivística está presente também com o uso da NOBRADE na descrição do acervo, e a aplicação da teoria arquivística ao verificarmos a distinção entre fundos e coleções conforme o guia. Em detrimento dessa constatação, chama nossa atenção, a ausência do profissional arquivista na composição do quadro funcional da instituição. Apesar de não ter arquivistas, o trabalho desenvolvido pela atual equipe do CEDEM, tem sido realizado de forma empenhada e coerente com as discussões da área arquivística. Em relação as linhas abordadas nos debates e eventos realizados pelo CEDEM, tem-se o gráfico abaixo.

\section{Gráfico 1 - Debates e Eventos realizados pelo CEDEM (2015-2018)}

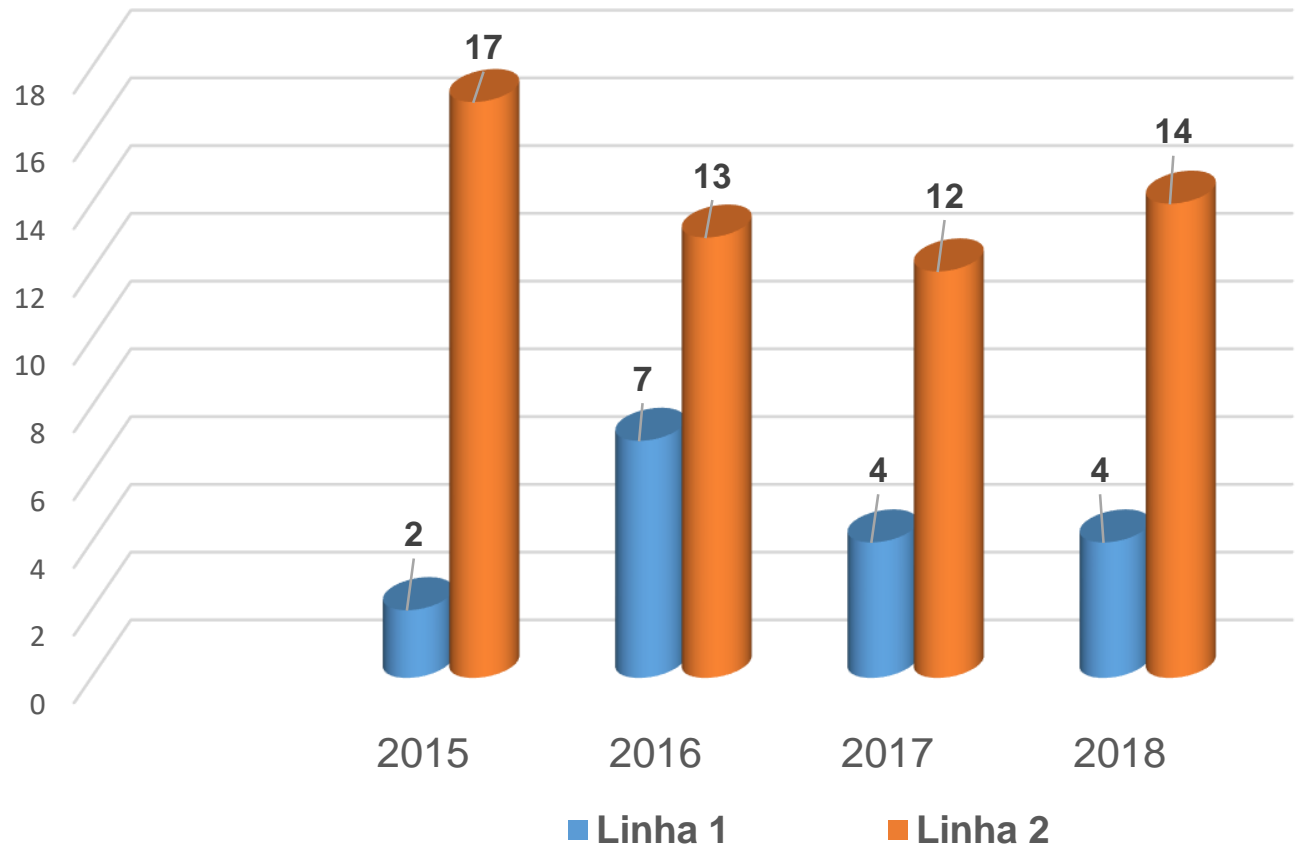

Fonte: Elaborado pelos autores com base nos Relatórios Anuais de Gestão (2015-2018).

Constatamos, a partir da análise do gráfico, que há poucas discussões referentes a linha 1 da instituição: Memória Universitária, e prevalece, majoritariamente discussões a respeito da linha 2, Memória dos Movimentos Político-Sociais Brasileiros Contemporâneo. Neste caso, pensamos que um dos caminhos possíveis para equilibrar essa distância entre as linhas seria a mescla 
de temas que comportassem as duas.

\section{CONCLUSÕES}

Sobre as ações realizadas em âmbito para difusão do acervo e da instituição em síntese verificamos que a instituição tem em suas atividades, ações que são realizadas para atender a seus objetivos propostos, ao fazer a difusão do patrimônio documental da universidade e dos documentos dos movimentos sociais que custodiam, com preocupação na preservação digital e física dos acervos; abordagens de caráter educativo para difusão; inserção das suas discussões em mídias sociais (tais como, Facebook e YouTube); além da criação de um ambiente para debates (realizados na própria sede da instituição e transmitidos online nas mídias sociais, abertos e de forma gratuita).

Além de promover reflexões sobre temáticas a respeito de movimentos sociais; política brasileira e internacional; questões de gêneros; lançamentos de livros, entre tantos outros importantes.

Verificamos ainda que, no CEDEM, a linha 2- Memória dos Movimentos Político-Sociais Brasileiros Contemporâneos possui em termos quantitativos mais eventos, como por exemplo, realizados nos Debates CEDEM.

Esse aspecto é muito importante do ponto de vista democrático, pois, como Cavalcanti (2014) aborda em sua tese, no geral os centros de documentação universitários atuam como espaços que dão relevância institucional às memórias de grupos que estão marginalizados da história oficial.

Assim, instituições como, arquivos, bibliotecas, museus, centros de documentação e memória, em razão de demandas sociais, passam a serem lugares de guarda e acesso do patrimônio documental e artístico de uma determinada época de uma sociedade. Nesse sentido, entende-se, que o contato com os documentos, sua 'energia' e simbolismo "tem a força de simular o transporte no tempo, à imersão na experiência vivida, de forma direta, sem mediações" (HEYMANN, 1997, p. 41).

Por fim, ao finalizar essas análises sintetizamos com alguns pontos que coloca o CEDEM como uma instituição preocupada e atuante no debate público 
ao:

- constituir-se como um espaço social que promove debates cujos os temas estão na ordem do dia, colaborando para o que há de mais importante na universidade: o diálogo;

- atender a uma demanda social para conhecimento ao passado, promovendo acesso, que perpassam pelos registros documentais;

- promover por meio do seu acervo, e com suas ações de preservação, guarda, acesso e difusão com a comunidade científica, movimentos sociais e públicos em geral, sendo por isso referência para novas pesquisas acadêmicas.

Por fim, enfatizamos que num contexto social de intolerâncias de todas as ordens, esquecimentos "forçados" e disputas por narrativas, faz-se necessário refletir e discutir acerca da importância da atuação de instituições de preservação do patrimônio documental, como o CEDEM e tantas outras cujo compromisso é a promoção da cidadania, por meio da preservação, guarda, acesso e difusão da memória documental e de movimentos sociais significativos para a nossa história.

\section{REFERÊNCIAS}

BELLOTTO, Heloísa Liberalli. Arquivos Permanentes: tratamento documental. 4. ed. Rio de Janeiro: Editora FGV, 2007.

CABRAL, Rosimere Mendes. Arquivo como fonte de difusão cultural e educativa. Acervo, Rio de Janeiro, v. 25, n. 1, p. 35- 44, 22 oct. 2012. Disponível em:

http://revista.arquivonacional.gov.br/index.php/revistaacervo/article/view/336. Acesso em: 10 dez. 2019.

CAMARGO, C. Centros de documentação e pesquisa histórica: uma trajetória de três décadas. In: CPDOC 30 anos. Rio de Janeiro: Ed. Fundação Getúlio Vargas/CPDOC, 2003. 192 p. Disponível em:

http://bibliotecadigital.fgv.br/dspace/themes/Mirage2/pages/pdfjs/web/viewer.ht $\mathrm{ml}$ ?file=http://bibliotecadigital.fgv.br/dspace/bitstream/handle/10438/6714/1350. pdf?sequence=1\&isAllowed=y. Acesso em: 10 nov. 2020.

CAMARGO, Ana Maria; GOULART, Silvana. Centros de memórias: uma proposta de definição. São Paulo: Edições SESC São Paulo, 2015.

CAVALCANTI, Marcia Teixeira. Os centros de documentação universitários como espaços de institucionalização de "novas" memórias. 2014. 190 f. 
Tese (Doutorado em Ciência da Informação) - Universidade Federal do Rio de Janeiro, Escola da Comunicação, Instituto Brasileiro de Informação em Ciência e Tecnologia, Programa de Pós-Graduação em Ciência da Informação, Rio de Janeiro, 2014. Disponível em:

https://ridi.ibict.br/bitstream/123456789/842/1/TESE\%20VERS\%c3\%830\%20FI NAL.pdf. Acesso em: 07 out. 2019.

CORRÊA, Anna Maria Martinez. Os Centros de Documentação e Memória da Unesp. O Centro de Documentação e Memória (CEDEM). In: SILVA, Zélia Lopes da (org.). Arquivos, Patrimônio e Memória, trajetórias e perspectivas. São Paulo: Editora UNESP, 1999, p. 80-81.

HEYMANN, Luaciana Quillet. Indivíduo, Memória e Resíduo Histórico: uma reflexão sobre arquivos pessoais e o caso Filinto Müller. Revista Estudos Históricos, Rio de Janeiro, v. 10, n. 19, 1997. Disponível em: http://bibliotecadigital.fgv.br/ojs/index.php/reh/article/view/2041. Acesso em: 20 dez. 2019.

ITAÚ CULTURAL. Centros de memória: manual básico para implantação. São Paulo: Itaú Cultural, 2013. 80 p. Disponível em:

http://d3nv1jy4u7zmsc.cloudfront.net/wp-content/uploads/2013/11/CM_web.pdf. Acesso em: 10 dez. 2019.

MORAES, Sandra. (org.). Guia do Acervo - Cedem. 2. ed. São Paulo: Cedem/UNESP, 2018. 148 p. Disponível em:

https://www.cedem.unesp.br/Modulos/Noticias/312/guia_cedem_2018-1.pdf. Acesso em: 05 jun. 2019.

POLLAK, Michael. Memória e identidade social. Estudos Históricos, Rio de Janeiro, v. 5, n. 10, 1992, p. 200-212. Disponível em:

http://www.pgedf.ufpr.br/memoria\%20e\%20identidadesocial\%20A\%20capraro \%202.pdf. Acesso em: 10 jun. 2019.

TANNO, Janete Leiko. Centros de documentação e patrimônio documental: direito à informação, à memória e à cidadania. Acervo, Rio de Janeiro, v. 31, n. 3, p. 88-101, 10 dic. 2018. Disponível em:

http://revista.arquivonacional.gov.br/index.php/revistaacervo/article/view/903. Acesso em: 13 dez. 2019.

TESSITORE, Viviane. Como implantar centros de documentação. São Paulo: Arquivo de Estado, Imprensa Oficial, 2003. 52 p. (Projeto como fazer, 09). Disponível em:

http://www.arquivoestado.sp.gov.br/site/assets/publicacao/anexo/como_implant ar_centros_de_documentacao.pdf.

TROITIÑO, Sonia. Avaliar para incorporar: políticas institucionais de formação de acervo. Resgate, Campinas, v. 24, n. 2, p. 27-46, jul./dez. 2016. Disponível em: https://issuu.com/centrodememoriaunicamp/docs/resgate_32_completa. 
TROITIÑO, Sonia. De interesse público: Política de aquisição de acervos como instrumento de preservação de documentos. Revista do Arquivo, São Paulo, n. 4, 2017. Disponível em:

http://www.arquivoestado.sp.gov.br/revista_do_arquivo/04/artigo_04.php.

Acesso em: 13 dez. 2019.

TROITIÑO, Sonia. Relatório Anual de Gestão 2014-2016 do Centro de

Documentação e Memória da Unesp - CEDEM. 2018. Não publicado.

TROITIÑO, Sonia. Relatório Anual de Gestão 2017 do Centro de

Documentação e Memória da Unesp - CEDEM. 2018. Não publicado.

TROITIÑO, Sonia. Relatório Anual de Gestão 2018 do Centro de

Documentação e Memória da Unesp - CEDEM. 2019. Não publicado.

\title{
AT THE REACH OF SOCIETY: ANALYSIS OF THE DISSEMINATION OF THE UNESP DOCUMENTATION AND MEMORY CENTER (2015-2018)
}

\begin{abstract}
Introduction: The collective and social memory is the object of many political, ideological, economic and cultural interests. Thus, public institutions focused on safeguarding documents assume a central role in the preservation of memory. Among them, we highlight the Center for Documentation and Memory (CEDEM) of the Universidade Estadual Paulista "Júlio de Mesquita Filho" - UNESP, which is constituted as a memory institution with two thematic lines: University Memory and Memory of Contemporary Brazilian Social-Political Movements. Objective: To analyze the dissemination actions developed by CEDEM. Methodology: The research methodology is bibliographic and descriptive, based on scientific literature in the field of archival science and related areas of memory, and annual management reports from 2015 to 2018. Results: We verified that the institution has in its activities, dissemination actions that are carried out to meet its proposed objectives. Conclusions: The institution preserves, guards, provides access to and disseminates the documentary heritage of the university and social movements, with concern for the digital and physical preservation of collections; educational approaches for dissemination; insertion of their discussions in social media (such as Facebook and YouTube); in addition to creating an environment for debates (held at the headquarters of the institution and broadcast online in social media, all open and free of charge), we highlight in this sense that there are reflections on issues concerning social movements; Brazilian and international politics; gender issues; book launches.
\end{abstract}

Descriptors: Documentation Center. Memory Center. CEDEM. Institutional Memory. Dissemination.

\section{EL ALCANCE DE LA SOCIEDAD: ANÁLISIS DE LAS MEDIDAS DE DIFUSIÓN DEL CENTRO DE}




\title{
DOCUMENTACIÓN Y MEMORIA DE LA UNESP (2015- 2018)
}

\begin{abstract}
RESUMEN
Introducción: La memoria colectiva y social es objeto de muchos intereses políticos, ideológicos, económicos y culturales. Así pues, las instituciones públicas centradas en la salvaguardia de los documentos asumen un papel central en la preservación de la memoria. Entre ellos, destacamos el Centro de Documentação e Memória (CEDEM) de la Universidade Estadual Paulista "Júlio de Mesquita Filho" - UNESP, que se constituye como una institución de memoria con dos líneas temáticas: Memoria Universitaria y Memoria de los Movimientos Socio-Políticos Brasileños Contemporáneos. Objetivo: Analizar las acciones de difusión desarrolladas por el CEDEM. Metodología: La metodología de investigación es bibliográfica y descriptiva, basada en la literatura científica en el área de la archivística y áreas relacionadas con la memoria, y los informes anuales de gestión de 2015 a 2018. Resultados: Comprobamos que la institución tiene en sus actividades, acciones de difusión que se llevan a cabo para cumplir con los objetivos propuestos. Conclusiones: La institución preserva, custodia, da acceso y difunde el patrimonio documental de la universidad y de los movimientos sociales, preocupándose por la preservación digital y física de los fondos; enfoques educativos para la difusión; inserción de sus debates en los medios de comunicación social (como Facebook y YouTube); además de crear un entorno para los debates (que se celebran en la sede de la institución y se difunden en línea en los medios de comunicación social, todos ellos abiertos y gratuitos), destacamos en este sentido que hay reflexiones sobre cuestiones relativas a los movimientos sociales; la política brasileña e internacional; las cuestiones de género; los lanzamientos de libros.
\end{abstract}

Descriptores: Centro de Documentación. Centro de la memoria. CEDEM. Memoria Institucional. Difusión.

Recebido em: 15.11 .2020

Aceito em: 18.11 .2020 